\title{
Declaration of San Antonio, Texas
}

\author{
San Antonio, Tex., July 14, 2007
}

Members of the International Society for Vascular Behavioral and Cognitive Disorders (Vas-Cog), representing 41 countries, met in San Antonio, Tex., USA, for the Third Vas-Cog International Congress (July 11-14, 2007). The Vas-Cog society members express hereby their concern with the worldwide declining support and lack of interest of Public Health services, scientific funding agencies, and pharmaceutical industry on the brain at risk from vascular factors and stroke.

- Despite the fact that prevention and early treatment of vascular disease are widely available at reasonable cost, almost all countries face the more expensive option of paying the expenses of hospitalization, nursing home, and loss of labor and life resulting from stroke, heart disease and dementia as a consequence of untreated vascular risk factors.

- Despite evidence of successful prevention of dementia by treatment with antihypertensive medications, no current trials have addressed this obviously cost-effective approach of major importance in health economics.

- Despite advances in the treatment of hypertension, diabetes, hyperlipidemia and other causes of stroke and heart disease, almost no recent studies have addressed the effects of these treatments on the prevention of vascular cognitive impairment and vascular dementia.

- Despite the fact that cerebrovascular disease and cardiovascular disease are the most common contributors to cognitive decline in older persons, and despite evidence that the combination of cerebrovascular disease and Alzheimer's disease is the most common pathological finding in dementia, there has been only limited research on the interaction of these two disease processes as a cause of dementia.

- Despite the fact that one in three stroke survivors are left incapacitated with vascular dementia and that as many as two thirds have behavioral and cognitive changes such as depression, apathy and intellectual decline, few stroke trials include cognitive and behavioral endpoints in the evaluation of new treatments for stroke.
- Despite the fact that vascular dementia is the second-most common form of dementia in the elderly after Alzheimer's disease, very few trials are being conducted on the use of existing and developing therapies for this devastating condition.

Therefore, it is the hope of the members of this international scientific society that Governments around the world, scientific funding agencies, and the pharmaceutical industry will recognize the importance of this problem and implement Public Health and research programs for the prevention and treatment of the deleterious consequences of vascular injury to the brain.

\section{By the Executive Committee of Vas-Cog on behalf of the} General Assembly

Vladimir Hachinski, MD, FRCPC, MSc, DSc, Hon. Dr. med. (Professor of Neurology, University of Western Ontario, London, Ont., Canada), Chairman

Ingmar Skoog, MD, PhD (Professor of Neuropsychiatric Epidemiology, Neuropsykiatri SU/Mölndal, Sweden), Secretary General

Philip Scheltens, MD, PhD (Professor of Cognitive Neurology and Director of the Alzheimer Center, Vrije Universiteit Medical Center, Amsterdam, The Netherlands), Treasurer

Anders Wallin, MD, PhD (Professor of Neurology and Geriatric Neuropsychiatry, Göteborg University and Sahlgrenska University Hospital, Göteborg, Sweden), Vice-Secretary

Timo Erkinjuntti, MD, PhD (Professor of Neurology and Director of the Memory Research Unit, University of Helsinki and Helsinki University Central Hospital, Finland), Coordinator Working Groups

Ken Nagata, MD, PhD (Director of Neurology, Research Institute for Brain and Blood Vessels, Akita, Japan), Coordinator VasCog Asia

Florence Pasquier, MD, PhD (Professor of Neurology and Head of the Memory Clinic, Lille University Hospital, Lille, France), Chair Membership Committee

\section{KARGER}

Fax +41 613061234 E-Mail karger@karger.ch www.karger.com
(C) 2007 S. Karger AG, Basel

0251-5350/07/0283-0191\$23.50/0 
Monique M.B. Breteler, MD, PhD (Professor of Neuroepidemiology, Head of the Neuroepidemiology Section, Department of Epidemiology and Biostatistics, Erasmus University Medical Centre, Rotterdam, The Netherlands)

Charles DeCarli, MD (Professor of Neurology and Director of the UC Davis Alzheimer's Disease Center and Imaging of Dementia and Aging Laboratory, Department of Neurology and Center for Neuroscience, University of California at Davis, Sacramento, USA)

Rajesh N. Kalaria, PhD, FRCPath. (Professor of Neuropathology, Institute for Ageing and Health, Wolfson Research Centre (Neuropathology), Newcastle General Hospital, Newcastle upon Tyne, UK), Chair Scientific Committee San Antonio, Tex. 2007 and Singapore 2009

Christopher Chen Li Hsian, BMBCh (Oxford), MRCP (UK), FAMS (Neurology), FRCP (Edin) (National Neuroscience Institute and Singapore General Hospital, Singapore), Local Organizer Vas-Cog 2009 Singapore

Donald R. Royall, MD (Professor of Psychiatry and Director of the Geriatric Psychiatry Division, University of Texas Health
Science Center and the Geriatric Research Center, Veterans Administration Hospital, San Antonio, Texas, USA), Local Organizer Vas-Cog 2007 San Antonio, Tex., USA

Gustavo C. Román, MD, FACP, FRSM (Lond.) (Professor of Medicine/Neurology and Director of the Memory Clinic, University of Texas Health Science Center and the Geriatric Research Center, Veterans Administration Hospital, San Antonio, Texas, USA), Local Organizer Vas-Cog 2007 San Antonio, Tex., USA

\section{Countries Represented}

Argentina, Australia, Austria, Bolivia, Brazil, Canada, Chile, China, Colombia, Croatia, Denmark, Finland, France, Germany, Hong Kong, India, Indonesia, Israel, Italy, Japan, Republic of Korea, Mexico, Netherlands, New Zealand, Nigeria, Norway, Poland, Portugal, Russian Federation, Serbia and Montenegro, Singapore, Spain, Sri Lanka, Sweden, Switzerland, Taiwan, Thailand, Trinidad and Tobago, United Kingdom, United States, Venezuela. 